\title{
Effect of early feed type exposure on diet-selection behavior of dairy calves
}

\author{
E. K. Miller-Cushon and T. J. DeVries ${ }^{1}$ \\ Department of Animal and Poultry Science, University of Guelph, Kemptville, ON, Canada KOG 1J0
}

\begin{abstract}
Dairy cattle exhibit characteristic feeding behavior patterns that may be influenced by early experiences. The objective of this study was to determine how early exposure to different feed types affects diet selection behavior of dairy calves once fed a mixed ration after weaning off milk. Eight Holstein bull calves were randomly assigned at birth to a feed exposure treatment: concentrate or grass/alfalfa hay, offered ad libitum. All calves were offered $8 \mathrm{~L} / \mathrm{d}$ of milk replacer $[1.2 \mathrm{~kg}$ of dry matter (DM)] from birth, which was incrementally reduced after 4 wk to enable weaning by the end of wk 7 . After milk weaning, all calves were fed a mixed ration containing (on a DM basis) 60\% concentrate and $40 \%$ grass/alfalfa hay for 9 wk. Intake was recorded daily, and calves were weighed 3 times/wk. Samples of fresh feed and orts were taken in wk 8, 12, and 16 for particle size analysis. The separator had 3 screens $(19,8$, and $1.18 \mathrm{~mm}$ ) producing long, medium, short, and fine particle fractions. Sorting of each fraction was calculated as actual intake as a percentage of predicted intake. Calves exposed to concentrate tended to have greater DM intake than calves exposed to hay both before (0.49 vs. $0.16 \mathrm{~kg} / \mathrm{d}$ ) and after weaning off milk (3.3 vs. 2.6 $\mathrm{kg} / \mathrm{d}$ ). Weights were similar during the milk-feeding stage, but calves exposed to concentrate had greater weights overall in the postweaning stage (129.8 vs. 112.6 $\mathrm{kg}$ ). Initially after weaning, calves sorted for familiar feed; calves previously exposed to concentrate sorted for short particles (126.4\%), which were primarily concentrate, whereas calves previously exposed to hay did not $(94.2 \%)$. Calves previously exposed to hay tended to sort for long particles $(113.4 \%)$, which were solely hay, whereas calves previously exposed to concentrate sorted against them (56.4\%). The sorting observed for short particles was associated with consuming a diet with a greater concentration of protein, nonfiber carbohydrates, and metabolizable energy, whereas sorting for long particles was associated with consuming a diet with a greater concentration of neutral detergent fiber. After $4 \mathrm{wk}$ of exposure to the mixed ration, sorting
\end{abstract}

Received April 27, 2010.

Accepted September 14, 2010.

${ }^{1}$ Corresponding author: tdevries@kemptvillec.uoguelph.ca was similar between treatments, with calves in both treatment groups sorting for short (117.4 and 120.5\%) and against long (62.4 and 54.4\%) particles, and consuming a diet with a similar concentration of nutrients and energy. These results indicate that feed familiarity affected initial diet selection postweaning, but may not have a lasting effect, with all calves developing similar feed-sorting patterns.

Key words: feed sorting, dairy calf, learning

\section{INTRODUCTION}

Dairy cattle are commonly fed a TMR containing a variety of feed components differing in particle size and nutritional content. The purpose of this feeding method is to encourage the consumption of a balanced ration formulated to meet nutritional requirements. However, dairy cattle frequently engage in a behavior known as "sorting," where they selectively consume certain components of their mixed ration. This results in an unbalanced intake of nutrients and can have health consequences for the animal (Stone, 2004; DeVries et al., 2008). Dairy cattle are commonly reported as sorting against the long-particle fraction and for the short-particle fraction of their ration (Leonardi and Armentano, 2003; DeVries et al., 2007); however, there is often high variation between cattle in the extent of their sorting behavior, as well as the pattern of their sorting (Leonardi and Armentano, 2003; Miller-Cushon and DeVries, 2010). Little is known about the learning and development of sorting behavior in dairy cattle and about factors that may influence the long-term variation in sorting behavior between dairy cattle.

Experiences early in life have been shown to affect the learning of feeding behavior in ruminants, with differences in feed preferences greatest when experiences occur earlier rather than later in life (Arnold and Maller, 1977; Provenza and Balph, 1987; Nolte et al., 1990). Specifically, evidence exists that feed exposure during the period of transition from nonruminant to ruminant (4 to 8 wk of life) feeding may be particularly influential in learning feeding behavior (Squibb et al., 1990). For cattle, the learning and development of foraging skills is strongly influenced by experience, as motor skills are perfected through repeated perfor- 
mance (Bandura, 1977), and these improve with more experience (Provenza and Balph, 1987). This suggests that exposure to different feed types early in life may affect feed selection of cattle later on in life. It is known that feeding behavior patterns of younger animals are less stable than those of adult animals (Provenza and Balph, 1988), but the age at which long-term feeding behaviors begin to take shape as well as factors influential in their development are poorly understood.

Dairy calves are exposed to solid feed early in life, as it is typically provided during the milk-feeding stage to help transition the calf from a preruminant animal to a functioning ruminant (Warner et al., 1956). Many practices are currently employed in the dairy industry to provide solid feed to preruminant calves, including providing only concentrates, only forages, or both. Concentrate feeding has traditionally been promoted because the fermentation of concentrates in the rumen results in the production of VFA, which are required for normal development of rumen papillae (Sander et al., 1959; Harrison et al., 1960). Interestingly, this development may progress out of step with the muscular development of the rumen, which is mainly a result of forage consumption (Tamate et al., 1962; Hamada et al., 1976). Despite resulting in early differences in rumen development, the ingestion of different feed types early in life does not permanently affect the ability of the calf to digest either concentrates or hay (Stobo et al., 1966b). It is unknown whether exposure of different feed types to calves during the milk-feeding stage has a long-term effect on their feed preferences and selection once they are fed a mixed ration.

Therefore, the objectives of this study were (1) to examine the effects of preweaning feed type exposure on feed-sorting behavior of calves once they have been transitioned to a common mixed ration after weaning off milk, and (2) to determine the longevity of any behavioral differences between calves exposed to different feed types. The hypothesis of this study was that calves would select in favor of feed components to which they had been exposed during the milk-feeding stage and that this selection would persist over time.

\section{MATERIALS AND METHODS}

\section{Animals and Housing}

Eight male Holstein calves were used in this study. Calves received colostrum (at least $4 \mathrm{~L}$ within the first $12 \mathrm{~h}$ of life) and were enrolled in the study within $24 \mathrm{~h}$ of birth. All calves received $2 \mathrm{~mL}$ of a vitamin supplement containing vitamins A, D, and E (E-Master, Vétoquinol Canada Inc., Lavaltrie, QC, Canada) and $1 \mathrm{~mL}$ of selenium (Dystosel, Pfizer Animal Health, Kirkland, QC,
Canada) i.m. on the day they were placed on the study. Calves $(\mathrm{n}=2)$ received electrolytes if it were noted that they were scouring for more than $1 \mathrm{~d}$; none of this scouring occurred past the first 2 wk of life, and no serious cases of illness occurred that required treatment. Calves were tethered within individual polyethylene hutches $(1.2 \mathrm{~m}$ wide $\times 2.4 \mathrm{~m}$ deep $)$ at the University of Guelph Kemptville Campus Dairy Education and Research Centre (Kemptville, ON, Canada) and were managed according to the standard operating procedures of this research station, in accordance with guidelines set by the Canadian Council on Animal Care (1993). Hutch placement prevented physical contact between calves but allowed for them to be in visual and auditory range. The interior of the hutch was bedded according to standard operating procedures of the research herd; straw was used for the first $3 \mathrm{wk}$ of life for all calves (to minimize risk of respiratory passage blockage), and then bedding was replaced with wood shavings. Bedding was replenished and replaced as needed, with fresh bedding added weekly at minimum. The insides of the hutches were cleaned biweekly or as needed. Hutches were placed under a 3 -sided, roofed shelter to protect from excessive exposure to the elements.

\section{Milk Feeding Procedure}

During the milk feeding stage, calves were fed acidified milk replacer by teat. The feeding setup involved a rubber teat protruding into the side of the hutch, attached to a tube fitted with a 1-way valve running into buckets placed adjacent to the hutches. All buckets, lines, and teats were removed for cleaning before each feeding. Calves were fed $22 \% \mathrm{CP}$ and $18 \%$ fat (Shur-Gain High-Performance Milk Replacer, Nutreco Canada Inc., Guelph, ON, Canada). Each liter of prepared milk replacer contained $150 \mathrm{~g}$ of powder as indicated; the powder was combined with hot water at a rate of $150 \mathrm{~g}$ of powder per $1 / 4 \mathrm{~L}$, with additional cold water added to reach the final volume. After 39 d of life, calves were switched to $21 \% \mathrm{CP}$ and $14 \%$ fat (Wet Nurse Calf Milk Replacer, PMT Inc., Regina, SK, Canada) for the last $10 \mathrm{~d}$ of the milk-feeding stage. Milk replacer was mixed daily in sufficient volume to feed all calves. At the time of preparation, a prediluted form of formic acid (acidified milk solution, 9.8\% formic acid; NOD Apiary Products Ltd., Frankford, ON, Canada) was added to acidify the milk replacer to a target $\mathrm{pH}$ between 4.0 and 4.3 to prevent microbial growth over the course of the day. All calves were fed twice daily at 0800 and $1600 \mathrm{~h}$ a fixed amount of $8 \mathrm{~L} / \mathrm{d}$ $(1.2 \mathrm{~kg}$ of DM) for the first $4 \mathrm{wk}$. To facilitate weaning, the amount of milk replacer offered was decreased to 6 $\mathrm{L} / \mathrm{d}(0.9 \mathrm{~kg}$ of DM) during wk $5,4 \mathrm{~L} / \mathrm{d}(0.6 \mathrm{~kg}$ of DM) 
during wk 6 , and then decreased incrementally daily during wk 7. Any milk remaining before the next fresh milk delivery was recorded throughout the milk-feeding stage to determine total daily milk intake. Calves had ad libitum access to water via a bucket inside their hutch for the duration of the study and water intake was recorded daily.

\section{Experimental Design and Diets}

Given the limited availability of calf housing, the sample size was restricted to a total of 8 calves. To ensure that the number of animals per treatment was adequate to detect statistical differences in treatment response, a power analysis (Morris, 1999; Hintze, 2008) was performed before the study for the primary response variables, including sorting, DMI, and ADG. Estimates of variation for these variables were based on previously reported values (Vazquez-Anon et al., 1993; Robblee et al., 2003; Abdelsamei et al., 2005; DeVries and von Keyserlingk, 2009). From the power analysis, it was determined that at $80 \%$ power, treatment differences of approximately $20 \%$ could be detected at this sample size.

Calves were randomly assigned to 1 of 2 feed exposure treatments: (1) exposure to concentrate offered ad libitum during the milk-feeding stage and (2) exposure to hay (first-cut 50:50 timothy grass/alfalfa mix) offered ad libitum during the milk-feeding stage. Birth weights were similar for both calves exposed to concentrate and calves exposed to hay $(47.0 \pm 3.4 \mathrm{~kg}$ and $45.8 \pm 2.2 \mathrm{~kg}$, respectively; $P=0.4$ ). Calves were offered their respective solid feed type (Table 1) beginning on the third day of life, once they were consuming milk independently and there was some possibility that they might investigate the solid feed offered. Calves remained on their respective feed exposure treatment for the duration of the milk-feeding stage. On the first day that milk was no longer offered, calves received a mixed ration containing, on a DM basis, $40 \%$ hay and $60 \%$ concentrate (Table 1) for an additional 9 wk. All calves received their solid feed in identical bins attached to the front of the hutch. During the preweaning stage, circular bins (diameter $=47.0 \mathrm{~cm}$, height $=21.6 \mathrm{~cm}$ ) were used for all calves, and during the postweaning stage, rectangular bins $(80.6 \mathrm{~cm}$ wide $\times$ $49.5 \mathrm{~cm}$ deep $\times 43.2 \mathrm{~cm}$ high) were used. Throughout the study, individual calf daily feed intake was recorded based on amount offered and refused by each calf. Feed was offered in sufficient amounts to ensure at least $15 \%$ orts such that feed was always available, despite some variability in day-to-day intake. Amount of feed offered daily to each calf was calculated based on the intake of that calf over the previous $3 \mathrm{~d}$. Actual percentage of orts was similar between weeks $(P=0.2)$ and similar for both concentrate and hay treatments (16.9 vs. $18.4 \%$; $\mathrm{SE}=1.4, P=0.3)$.

\section{Growth Measurements}

Calves were weighed at the same time each day on 2 consecutive days each week for the first $7 \mathrm{wk}$, and then weighed at the same time each day on 3 consecutive days each week for the remainder of the study. Repeated measurements were made to obtain an accurate weekly weight and to account for day-to-day variability. Scale malfunctions prevented accurate weights from being obtained on wk 8 and 9. Therefore, weight data for the postweaning stage contains only measurements taken during wk 10 to 16.

\section{Feed Sampling and Analysis}

For determination of DM and nutrient content of the feed and assessment of daily DMI of the calves, fresh feed was sampled weekly and individual orts from each calf were sampled daily on every second week (wk 4, 6, $8,10,12,14$, and 16), just before removal and delivery of fresh feed. This sampling protocol was consistent throughout the study; however, samples taken changed from either hay or grain during the milk-feeding stage, to mixed ration samples for the remainder of the study. Once calves were transitioned to the mixed ration, duplicate ort samples for particle size analysis were taken every second sampling week (on wk 8, 12, and 16). All samples were immediately frozen at $-20^{\circ} \mathrm{C}$ until they were further analyzed.

Samples for particle size analysis were separated using the 3-screen (19, 8, and $1.18 \mathrm{~mm}$ ) Penn State particle separator (Kononoff et al., 2003). This separated the particles into 4 fractions: long $(>19 \mathrm{~mm})$, medium $(<19,>8 \mathrm{~mm})$, short $(<8,>1.18 \mathrm{~mm})$, and fine $(<1.18 \mathrm{~mm})$ particles. After separation, the DM of each separated fraction was determined by oven drying at $55^{\circ} \mathrm{C}$ for $48 \mathrm{~h}$.

Samples taken for DM and chemical analysis were oven-dried at $55^{\circ} \mathrm{C}$ for $48 \mathrm{~h}$ and then ground to pass through a 1-mm screen (Wiley Mill, Arthur H. Thomas Co., Philadelphia, PA). These samples were then pooled by time intervals and treatment and sent to Cumberland Valley Analytical Services Inc. (Maugansville, MD) for analysis of $\mathrm{DM}\left(135^{\circ} \mathrm{C}\right.$; $\mathrm{AOAC}$, 2000: method 930.15), ash $\left(535^{\circ} \mathrm{C}\right.$; AOAC, 2000: method 942.05), ADF (AOAC, 2000: method 973.18), NDF with heat-stable $\alpha$-amylase and sodium sulfite (Van Soest et al., 1991), and CP $(\mathrm{N} \times 6.25$; AOAC 2000: method 990.03; Leco FP-528 nitrogen analyzer, Leco, St. Joseph, MI). 
Table 1. Chemical composition and particle size distributions of feed components and mixed ration (mean \pm $\mathrm{SD}$; DM basis)

\begin{tabular}{|c|c|c|c|}
\hline Item & Hay $^{1}$ & Concentrate $^{2}$ & $\begin{array}{l}\text { Mixed } \\
\text { ration }^{3}\end{array}$ \\
\hline \multicolumn{4}{|c|}{ Chemical composition $^{4}$} \\
\hline DM, \% & $91.0 \pm 1.8$ & $90.6 \pm 0.4$ & $90.7 \pm 1.1$ \\
\hline $\mathrm{OM}, \%$ of $\mathrm{DM}$ & $92.7 \pm 1.2$ & $92.1 \pm 0.7$ & $92.6 \pm 0.9$ \\
\hline $\mathrm{CP}, \%$ of $\mathrm{DM}$ & $10.4 \pm 1.1$ & $21.6 \pm 2.0$ & $16.5 \pm 1.0$ \\
\hline $\mathrm{ADF}, \%$ of $\mathrm{DM}$ & $42.5 \pm 0.8$ & $8.3 \pm 0.4$ & $23.9 \pm 2.3$ \\
\hline $\mathrm{NDF}, \%$ of DM & $67.2 \pm 0.8$ & $18.5 \pm 0.9$ & $38.2 \pm 4.0$ \\
\hline NFC, $\%$ of DM & $14.3 \pm 2.0$ & - & $36.1 \pm 4.0$ \\
\hline $\mathrm{ME}, \mathrm{Mcal} / \mathrm{kg} \mathrm{DM}$ & $1.97 \pm 0.03$ & - & $2.46 \pm 0.06$ \\
\hline \multicolumn{4}{|l|}{ Particles, ${ }^{5,6} \%$} \\
\hline Long particles & $67.9 \pm 5.9$ & 0 & $26.1 \pm 4.1$ \\
\hline Medium particles & $20.4 \pm 5.6$ & $14.4 \pm 6.6$ & $18.4 \pm 7.2$ \\
\hline Short particles & $9.6 \pm 2.1$ & $79.4 \pm 7.3$ & $50.2 \pm 4.3$ \\
\hline Fine particles & $2.1 \pm 0.8$ & $6.2 \pm 6.6$ & $5.3 \pm 4.0$ \\
\hline
\end{tabular}

${ }^{1}$ Hay was a first-cut mix of approximately $50 \%$ timothy grass and $50 \%$ alfalfa.

${ }^{2}$ Supplied by Rooney's Feeds (Iroquois, ON, Canada), containing (on as-is basis): $36.5 \%$ corn, $28 \%$ calf starter supplement (Shur-Gain, Nutreco Canada Inc., Guelph, ON, Canada), 20\% rolled barley, $10 \%$ rolled oats, $2.5 \%$ dilute monensin sodium, $2 \%$ molasses, $1 \%$ soybean oil.

${ }^{3}$ Mixed ration contained $60 \%$ concentrate and $40 \%$ hay (DM basis).

${ }^{4}$ Values were obtained from chemical analysis of feed samples. NFC $=100-(\% \mathrm{CP}+\% \mathrm{NDF}+\%$ fat + $\%$ ash). $\mathrm{ME}=$ total digestible nutrients $(\mathrm{TDN}) \times 0.04409 \times 0.82$ (calculated according to NRC, 2001 equations).

${ }^{5}$ Particle size was determined by a Penn State particle separator, which separates the particles into 4 fractions: long $(>19 \mathrm{~mm})$, medium $(<19,>8 \mathrm{~mm})$, short $(<8,>1.18 \mathrm{~mm})$, and fine $(<1.18 \mathrm{~mm})$.

${ }^{6} \mathrm{NDF}$ content, as a percentage of DM, of each particle size fraction of the mixed ration is as follows: long $=$ $69.7 \pm 1.3 \%$, medium $=40.0 \pm 0.2 \%$, short $=22.7 \pm 0.4 \%$, fine $=21.8 \pm 4.2 \%$.

\section{Calculations and Statistical Analyses}

Sorting activity for each fraction of the Penn State particle separator was calculated as the actual intake of each fraction expressed as a percentage of the predicted intake of that fraction (Leonardi and Armentano, 2003). The actual intake of each individual fraction was calculated as the difference between the DM amount of each fraction in the offered feed and that in the refused feed. The predicted intake for an individual fraction was calculated as the product of the DMI of the total diet multiplied by the DM percentage of that fraction in the fed TMR. Values equal to $100 \%$ indicate no sorting, $<100 \%$ indicate selective refusals (sorting against), and $>100 \%$ indicate preferential consumption (sorting for). Weekly ADG was calculated as the difference between weights taken 1 wk apart divided by 7 .

All data were summarized for each calf for each week (in which data were collected) on treatment. Data for DMI, weight gain, and ADG data were summarized and analyzed separately by stage of life (preweaning and postweaning). Data for nutrient intakes and DMI were additionally analyzed for weeks that coincided with feed-sorting analysis (wk 8, 12, and 16). To test whether sorting of the experimental diets occurred, sorting activity for each particle size fraction was tested for a difference from 100 using $t$-tests within the MIXED procedure of SAS (SAS Institute, 2003). To examine the effect of treatment, all data were analyzed using the MIXED procedure of SAS (SAS Institute, 2003), treating week as a repeated measure. The model included the fixed effects of week, treatment, and week $x$ treatment interaction, and the random effect of calf within treatment. Compound symmetry was selected as the variance-covariance matrix structure for the sorting data on the basis of best fit according to Schwarz's Bayesian information criterion. The autoregressive model was selected as the variance-covariance matrix structure for the intake, weight gain, and ADG data on the basis of best fit according to Schwarz's Bayesian information criterion. All values reported are least squares means. Significance was declared at $P \leq 0.05$, and trends reported if $0.05<P \leq 0.10$.

\section{RESULTS AND DISCUSSION}

During the milk-feeding stage (wk 1 to 7 ), calves were exposed to diets that differed both in particle size and nutrient composition (Table 1). Intakes and weight gain data for this stage are reported in Table 2. Calves exposed to concentrate tended to have greater DMI than calves exposed to hay in the preweaning stage, and a treatment $\times$ week interaction was found, with the calves exposed to concentrate increasing their DMI in wk 6 to a greater extent than calves exposed to hay. Similar weight gain occurred during this time, indicat- 
Table 2. Intakes and weight gain on treatment diets before and after weaning off milk ${ }^{1}$

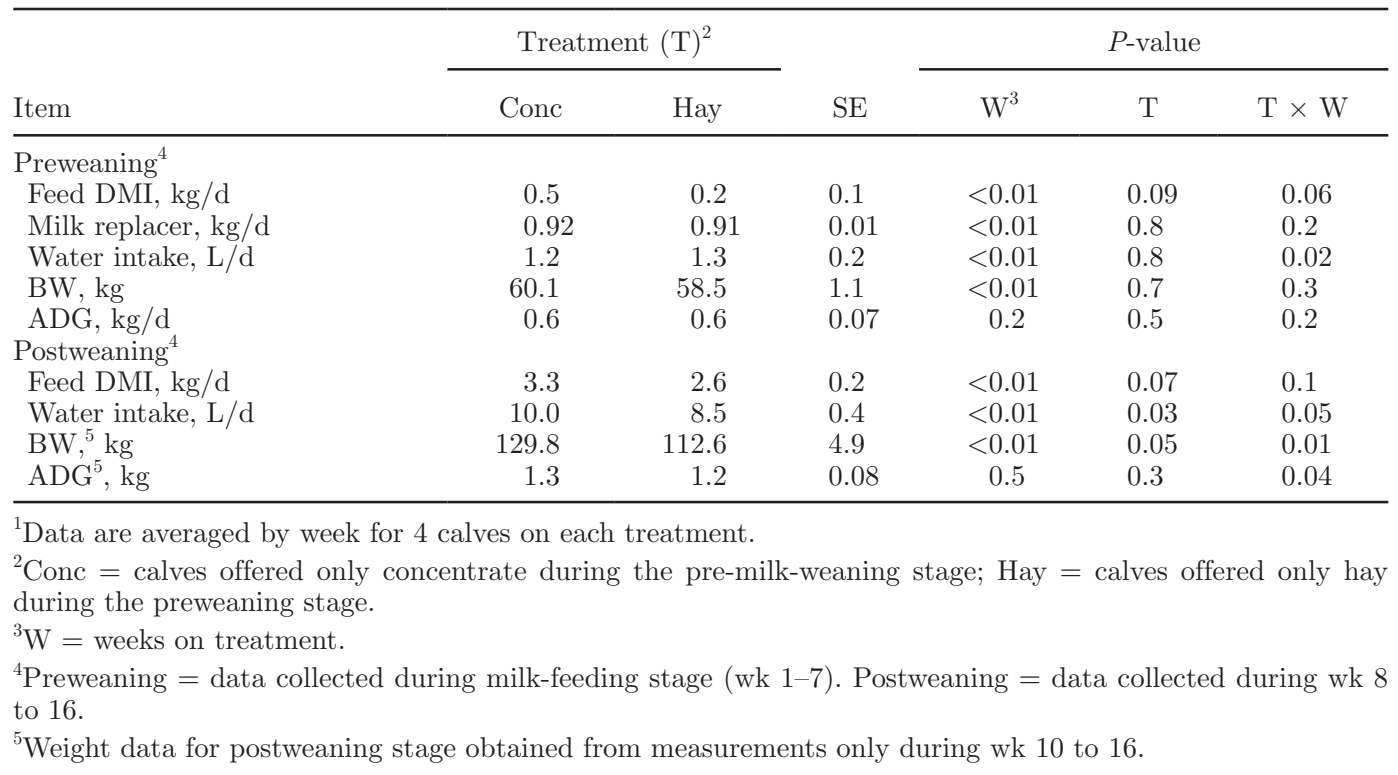

ing that growth was primarily dependent upon milk intake, which was similar between treatments, rather than the amount of solid feed intake, which differed.

During the postweaning stage (wk 8 to 16), all calves were fed a mixed ration containing both concentrate and hay (characterized in Table 1). The bulk of the mixed ration was composed of long and short particles, which together contributed over $75 \%$ of the total DM. Average intakes and weight gain data for this stage are reported in Table 2. Overall, in the postweaning stage, water intake was greater and DMI tended to be greater for calves previously exposed to concentrate. Weight data during the postweaning stage were based on measurements obtained only during wk 10 to 16 . During this time, weights were greater for calves previously exposed to concentrate than for calves previously exposed to hay, but ADG did not differ overall. It is apparent that calves exposed to concentrate in the milk-feeding stage experienced greater ADG immediately following transition to the mixed ration (wk 8 and 9), resulting in the difference in BW observed by wk $10(98.0 \mathrm{~kg}$ for calves previously exposed to concentrate, and $84.5 \mathrm{~kg}$ for calves previously exposed to hay; $\mathrm{SE}=4.5, P=$ 0.07). The ADG was similar between treatment groups by wk $10(P>0.1)$. Calves previously exposed to concentrate may have had greater ADG initially after milk weaning due to different effects of feed types on rumen development during the milk-feeding stage. It is well documented that rumen papillae growth is stimulated by the presence of VFA, which are produced in the fermentation of concentrates in the rumen (Sander et al., 1959; Harrison et al., 1960), and rumen papillae development is positively associated with weight gain (Stobo et al., 1966a).

Immediately following transition to the mixed ration (wk 8), differences were observed between treatments in sorting of the long-particle fraction, which was solely hay, and for the short-particle fraction, which was primarily concentrate. All calves previously exposed to concentrate began sorting their feed against the longparticle size fraction and for the short-particle size fraction, whereas calves previously exposed to hay tended to sort their feed for the long-particle size fraction (Table 3 ). These differences in sorting behavior resulted in different nutrient and energy intakes between treatment groups (Table 4) due to the differences in the nutrient content of concentrate and hay (Table 1). Sorting for short particles, which were primarily concentrate, was associated with consuming a diet with a greater concentration of CP, NFC, and ME (Table 4). Sorting for long particles, which were solely hay, was associated with consuming a diet with a greater concentration of NDF. Immediately following weaning, DMI was similar between treatment groups; therefore, calves previously exposed to concentrate were consuming greater total quantities of CP, NFC, and ME. This difference in nutrient intakes likely also influenced weight gain initially after transition to the mixed ration, as more energydense diets are known to promote greater weight gain in calves than diets with greater fiber content (Stobo et al., 1966a; Brown et al., 2005). Thus, differences in sorting behavior in wk 8 may have contributed to the difference in weights between treatment groups seen by wh 10. 
Table 3. Effect of feed exposure treatments on sorting (\%) of each particle-size fraction during postweaning stage

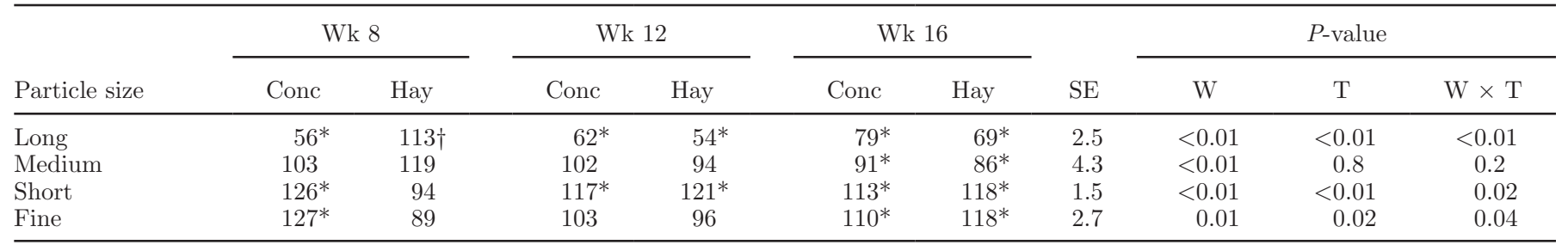

${ }^{1}$ Treatment $(\mathrm{T})$ : Conc = calves offered only concentrate during the milk-feeding stage (wk 1-7); Hay = calves offered only hay during the milkfeeding stage (wk 1-7). Sorting (\%) $=100 \times$ (particle size of DMI/particle size of predicted DMI). Sorting values equal to $100 \%$ indicate no sorting, $<100 \%$ indicate selective refusals (sorting against), and $>100 \%$ indicate preferential consumption (sorting for). Data are averaged over $7 \mathrm{~d}$ for each of 3 recording weeks (W) postweaning for 4 calves on each treatment. Particle size determined by Penn State particle separator, which separates the particles into 4 fractions: long $(>19 \mathrm{~mm})$, medium $(<19,>8 \mathrm{~mm})$, short $(<8,>1.18 \mathrm{~mm})$, and fine $(<1.18 \mathrm{~mm})$.

$* P \leq 0.05, \dagger P \leq 0.1$ : Difference in sorting values from $100 \%$.

Differences between treatment groups during wk 8 in sorting of long- and short-particle fractions, which closely represent hay and concentrate, respectively, indicate that once calves were transitioned to the mixed ration, they immediately began selecting in favor of the familiar feed component. To our knowledge, this is the first evidence to date that intensively raised dairy cattle that are this young will engage in feed-sorting behavior. Selection in favor of the familiar feed component was expected, because there is empirical evidence that early experience with different feed types influences later feeding behavior of ruminants (Provenza and Balph, 1987). For example, Phillips (2004) demonstrated that dairy calves offered cut grass during the milk-feeding stage grazed for longer periods when turned out to pasture after weaning. This suggests that early feed exposure may influence later feeding behavior, possibly shaping feed preferences or promoting development of necessary motor skills. Similarly, lambs have been shown to select in favor of feeds with flavors to which they have been exposed early in life (Simitzis et al., 2008), indicating that flavor familiarity may influence feed preferences. In the present study, selection in favor of the familiar feed immediately after weaning could be due to the presence of specific motor skills developed while consuming particles of a certain shape and size, as well as flavor and palatability familiarity. Alternatively, the pattern of feed selection seen immediately after weaning may have been motivated by a short-lived period of neophobia, wherein calves sorted for familiar feed out of an attempt to avoid the unfamiliar feed. Evidence exists that young ruminants, when presented with an unfamiliar feed, will initially consume only small amounts (Squibb et al., 1990).

The effect of exposure to different solid feed types during the preweaning stage did not have a long-lasting effect on sorting behavior, with all calves sorting similarly for the short-particle and against the long-particle fraction after 4 wk of experience with the common mixed ration (Table 3 ). It should be noted that a limitation of the present study was the small sample size used, and the resulting lack of power to detect small differences between treatments. Thus, it is possible that a larger sample size would reveal more subtle differences in long-term sorting behavior, due to early experience, than was presently detected. The similar pattern of

Table 4. Effect of feed exposure treatments on postweaning intakes of nutrients and energy ${ }^{1}$

\begin{tabular}{|c|c|c|c|c|c|c|c|c|c|c|}
\hline \multirow[b]{2}{*}{ Item } & \multicolumn{2}{|c|}{ Wk 8} & \multicolumn{2}{|c|}{ Wk 12} & \multicolumn{2}{|c|}{ Wk 16} & \multirow[b]{2}{*}{$\mathrm{SE}$} & \multicolumn{3}{|c|}{$P$-value } \\
\hline & Conc & Hay & Conc & Hay & Conc & Hay & & W & $\mathrm{T}$ & $\mathrm{W} \times \mathrm{T}$ \\
\hline $\mathrm{DMI},{ }^{2} \mathrm{~kg} / \mathrm{d}$ & 1.3 & 1.0 & 3.3 & 2.7 & 4.9 & 3.9 & 0.2 & $<0.01$ & 0.06 & 0.1 \\
\hline $\mathrm{CP}, \mathrm{kg} / \mathrm{d}$ & 0.23 & 0.18 & 0.59 & 0.51 & 0.88 & 0.72 & 0.02 & $<0.01$ & $<0.01$ & 0.3 \\
\hline $\mathrm{NFC}, \mathrm{kg} / \mathrm{d}$ & 0.61 & 0.45 & 1.5 & 1.3 & 1.8 & 1.5 & 0.05 & $<0.01$ & $<0.01$ & 0.7 \\
\hline ME, Mcal/d & 3.5 & 2.7 & 8.7 & 7.3 & 12.5 & 10.1 & 0.3 & $<0.01$ & $<0.01$ & 0.4 \\
\hline NFC, $\%$ of DMI & 48.7 & 44.0 & 46.4 & 48.9 & 37.2 & 39.6 & 0.8 & $<0.01$ & 1.0 & $<0.01$ \\
\hline ME, Mcal/kg of DMI & 2.75 & 2.66 & 2.65 & 2.70 & 2.55 & 2.60 & 0.05 & $<0.01$ & 1.0 & $<0.01$ \\
\hline
\end{tabular}

${ }^{1}$ Treatment $(\mathrm{T})$ : Conc = calves offered only concentrate during the milk-feeding stage (wk 1-7); Hay = calves offered only hay during the milkfeeding stage (wk 1-7). Data are averaged over $7 \mathrm{~d}$ for each of 3 recording weeks (W) for 4 calves on each treatment.

${ }^{2}$ Only DMI data from wk 8,12 , and 16 were used for this analysis. 
sorting after $4 \mathrm{wk}$ of experience with the mixed ration resulted in all calves consuming diets with similar concentrations of nutrients, explaining why there was no overall treatment effect in the postweaning stage on intake of nutrients as a percentage of DMI (Table 4).

The short duration of the selection in favor of the familiar feed is noteworthy, given that researchers have previously found longer-lasting effects of early feed exposure on feeding behavior. Simitzis et al. (2008) found that lambs would select at 11 mo of age for flavors that they had been exposed to no later than $55 \mathrm{~d}$ of age. As well, Squibb et al. (1990) found that lambs exposed to a shrub between 4 and 8 wk of age consumed more than naive lambs of the same age when offered the shrub again after 9 mo had passed. A variety of factors may have influenced the duration of the effects of different early feed exposure on feed sorting in the present study. As mentioned above, it is possible that neophobia was a factor motivating the initial differences seen in feed sorting behavior. Although young ruminants are often hesitant to consume a novel feedstuff initially, it has also been found that after a short period of experience, they will adapt to a novel feed and begin consuming it (Squibb et al., 1990). This may explain why the differences in sorting were short-lived. Further, given the multitude of factors that may contribute to the development of long-term feeding behavior, the short longevity of the effects of feed exposure may not be surprising. Nolte et al. (1990) found that the longevity of a feed preference established by early exposure to a feed type depended upon the initial acceptance of the feed type, with lambs failing to develop preferences for feeds they were reluctant to consume initially. This may be particularly relevant for the present study, as calves consumed less hay than concentrate initially, and calves previously exposed to hay then showed only a shortlived preference for hay once exposed to the mixed ration. It should be noted that social and maternal influences, which were not factors in the present study, seem to influence establishment of dietary habits (Provenza and Balph, 1988; Phillips, 2004). We encourage further research to discover the role of social environment in development of feed preferences. Another potentially influential factor is the age at which the animal is first exposed to a feed and the duration of the exposure to that feed. Most researchers have noted a longer term effect of early feed exposure when they carried their early feed or flavor exposure treatment past weaning (Nolte et al., 1990; Simitzis et al., 2008). In the present study, the feed exposure treatment ended at the time of milk weaning; thus, further research is encouraged to examine whether exposure to different feeds for a longer period encompassing milk weaning may cause longer lived differences in feed sorting behavior.
The pattern of sorting for concentrate and against hay seen in all calves after 4 wk on the mixed ration mimics sorting patterns often seen in adult cattle fiber (Leonardi and Armentano, 2003; DeVries et al., 2007), indicating that similar factors may contribute to dietary selection at different stages of life, regardless of early experience. Particle size itself may be a factor influencing selection. Sheep have been shown to prefer finely chopped forages over more coarsely chopped forages, which they cannot consume as quickly (Kenney and Black, 1984). Similarly, cattle may sort against long particles due to limitations they impose on rate of intake; cattle consume feeds that are fibrous and dry, such as hay, more slowly than they do pelleted concentrate feeds (Campling and Morgan, 1981). Feed flavor and palatability also may contribute to preferences for short particles commonly seen in adult cattle, as well as the calves in this study. Flavor preference tests have indicated that cattle have a strong preference for sweet flavors (Nombekela et al., 1994), possibly explaining preferences for the short-particle fraction, which is often high in sugar and starch. Dietary selection may also be related to learned associations with postingestive feedback. Evidence exists that young ruminants will develop long-term preferences for flavors associated with high-energy feeds (Burritt and Provenza, 1992), and researchers have shown that dietary selection is influenced by the nutritional and energy requirements of ruminants (Villalba and Provenza, 1999; Mellado et al., 2005). In the present study, preferences shown for the concentrate, which has greater energy content than hay, may have been influenced by energy demands of the calf. Thus, a variety of factors related to feed particle size, flavor, and nutritional content may influence dietary selection of cattle beginning at a young age, with cattle showing similar preferences for certain feed characteristics. These feed characteristics may influence or potentially override dietary selection habits developed as a result of early feed exposure.

Once similar sorting patterns had been established by all calves by wk 12 , sorting behavior was not static for the duration of the study. Between wk 12 and 16, changes were observed in the sorting of all particle fractions (Table 3). The changes in sorting of medium- and fine-particle fractions were not large and high variability was observed in sorting of these fractions, likely because they represented only a small percentage of the total ration. The changes in sorting of long- and shortparticle fractions are of more importance because of their large contribution to the total ration DM, as they closely represent the hay and concentrate, respectively. Calves within both treatment groups sorted against long particles (entirely composed of hay) to a lesser extent in wk 16 compared with wk 12. Calves previ- 
ously exposed to concentrate gradually increased their intake of long particles over the entire postweaning stage, whereas calves previously exposed to hay, after exhibiting a decrease in intake of long particles in wk 12 , began consuming more long particles again in wk 16. As well, calves previously exposed to concentrate decreased the extent of their sorting for short particles both in wk 12 and 16. As all calves lessened the extent of their sorting for short particles and against long particles in wk 16 compared with wk 12, they began consuming a diet with lower concentrations of $\mathrm{CP}$, $\mathrm{NFC}$, and $\mathrm{ME}$, and a greater concentration of NDF (Table 4). Changes in the extent of sorting by all calves indicate that, whereas early experience may not always have a long-term influence on sorting behavior, other external or internal factors continually influence these sorting patterns.

\section{CONCLUSIONS}

Exposure to different solid feed types during the milkfeeding stage influenced sorting behavior immediately after all calves were transitioned to a common mixed ration. Calves previously exposed to concentrate sorted the mixed ration in favor of the familiar feed component and calves previously exposed to hay tended to do so, influencing the concentration of nutrients consumed in the feed. However, after $4 \mathrm{wk}$ on a mixed ration, all calves exhibited a similar sorting pattern, sorting for the short- and against the long-particle fractions. These results suggest that different early feed exposure did not have a long-term effect on sorting behavior. However, this study was limited by a small sample size; therefore, subtle long-term differences in feeding behavior might be detected in a more powerful study with a greater number of treatment replicates. The results do indicate that properties of the feed itself may influence sorting patterns and play a greater role in feed sorting behavior than early feed experiences. This study also demonstrated that feed sorting behavior is not static, as patterns of sorting, as well as extent of sorting, varied over time, indicating the adaptability of this behavior from a young age.

\section{ACKNOWLEDGMENTS}

We thank the staff and students at the University of Guelph Kemptville Campus Dairy Education and Research Centre. In particular, we thank H. Migdal, M. Bruce, and S. Beckinsale of the University of Guelph Kemptville Campus for their technical assistance. We also would like to acknowledge support received from the Natural Sciences and Engineering Research Council of Canada (NSERC, Ottawa, ON, Canada).

\section{REFERENCES}

Abdelsamei, A. H., D. G. Fox, L. O. Tedeschi, M. L. Thonney, D. J. Ketchen, and J. R. Stouffer. 2005. The effect of milk intake on forage intake and growth of nursing calves. J. Anim. Sci. 83:940947.

AOAC. 2000. Official Methods of Analysis. Vol. I. 17th ed. Association of Official Analytical Chemists International, Arlington, Virginia.

Arnold, C. W., and R. A. Maller. 1977. Effects of nutritional experiences in early and adult life on the performance and dietary habit of sheep. Appl. Anim. Ethol. 3:5-26.

Bandura, A. 1977. Social Learning Theory. Prentice Hall, Englewood Cliffs, NJ.

Brown, E. G., M. J. VandeHaar, K. M. Daniels, J. S. Liesman, L. T. Chapin, D. H. Keisler, and M. S. Weber Nielsen. 2005. Effect of increasing energy and protein intake on body growth and carcass composition of heifer calves. J. Dairy Sci. 88:585-594.

Burritt, E. A., and F. D. Provenza. 1992. Lambs form preferences for nonnutritive flavors paired with glucose. J. Anim. Sci. 70:11331136.

Campling, R. C., and C. A. Morgan. 1981. Eating behavior of housed dairy cow-A review. Dairy Sci. 43:57-63. (Abstr.)

Canadian Council on Animal Care. 1993. Guide to the Care and Use of Experimental Animals. Vol. 1. E. D. Olfert, B. M. Cross, and A. A. McWilliam, ed. CCAC, Ottawa, ON, Canada.

DeVries, T. J., K. A. Beauchemin, and M. A. G. von Keyserlingk. 2007. Dietary forage concentrate affects the feed sorting behavior of lactating dairy cows. J. Dairy Sci. 90:5572-5579.

DeVries, T. J., F. Dohme, and K. A. Beauchemin. 2008. Repeated ruminal acidosis challenges in lactating dairy cows at high and low risk for developing acidosis: Feed sorting. J. Dairy Sci. 91:39583967.

DeVries, T. J., and M. A. G. von Keyserlingk. 2009. Feeding method affects the feeding behavior of growing dairy heifers. J. Dairy Sci. 92:1161-1168.

Hamada, T., S. Maeda, and K. Kameoka. 1976. Factors influencing growth of rumen, liver, and other organs in kids weaned from milk replacers to solid foods. J. Dairy Sci. 59:1110-1118.

Harrison, H. N., R. G. Warner, E. G. Sander, and J. K. Loosli. 1960. Changes in the tissue and volume of the stomachs of calves following the removal of dry feed or consumption of inert bulk. J. Dairy Sci. 43:1301-1312.

Hintze, J. 2008. PASS 2008. NCSS, LLC, Kaysville, UT.

Kenney, P. A., and J. L. Black. 1984. Factors affecting diet selection by sheep. 1. Potential intake rate and acceptability of feed. Aust. J. Agric. Res. 35:551-563.

Keunen, J. E., J. C. Plaizier, L. Kyriazakis, T. F. Duffield, T. M. Widowski, M. L. Lindinger, and B. W. McBride. 2002. Effects of a subacute ruminal acidosis model on the diet selection of dairy cows. J. Dairy Sci. 85:3304-3313.

Kononoff, P. J., A. J. Heinrichs, and D. R. Buckmaster. 2003. Modification of Penn State forage and total mixed ration particle separator and the effects of moisture content on its measurements. J. Dairy Sci. 86:1858-1863.

Leonardi, C., and L. E. Armentano. 2003. Effect of quantity, quality, and length of alfalfa hay on selective consumption by dairy cows. J. Dairy Sci. 86:557-564.

Mellado, M., A. Rodriguez, J. A. Villarreal, and A. Olvera. 2005. The effect of pregnancy and lactation of diet composition and dietary preference of goats in a desert rangeland. Small Rumin. Res. 58:79-85.

Miller-Cushon, E. K., and T. J. DeVries. 2010. Feeding amount affects the sorting behaviour of lactating dairy cows. Can. J. Anim. Sci. 90:1-7.

Morris, T. R. 1999. Experimental Design and Analysis in Animal Sciences. CABI Publishing, New York, NY.

National Research Council. 2001. Nutrient Requirements for Dairy Cattle. Natl. Acad. Sci., Washington, DC.

Nolte, D. L., F. D. Provenza, and D. F. Balph. 1990. The establishment and persistence of food preferences in lambs exposed to selected foods. J. Anim. Sci. 68:998-1002. 
Nombekela, S. W., M. R. Murphy, H. W. Gonyou, and J. I. Marden. 1994. Dietary preferences in early lactation cows as affected by primary tastes and some common feed flavors. J. Dairy Sci. 77:2393-2399.

Phillips, C. J. C. 2004. The effects of forage provision and group size on the behaviour of calves. J. Dairy Sci. 87:1380-1388.

Provenza, F. D., and D. F. Balph. 1987. Diet learning by domestic ruminants: Theory, evidence and practical implications. Appl. Anim. Behav. 18:211-232.

Provenza, F. D., and D. F. Balph. 1988. Development of dietary choice in livestock on rangelands and its implications for management. J. Anim. Sci. 66:2356-2368.

Robblee, E. D., P. S. Erickson, N. L. Whitehouse, A. M. McLaughlin, C. G. Schwab, J. J. Rejman, and R. E. Rompala. 2003. Supplemental lactoferrin improves health and growth of Holstein calves during the preweaning phase. J. Dairy Sci. 86:1458-1464.

Sander, E. G., R. G. Warner, H. N. Harrison, and J. K. Loosli. 1959. The stimulatory effect of sodium butyrate and sodium propionate on the development of rumen mucosa in the young calf. J. Dairy Sci. 42:1600-1605.

SAS Institute. 2003. SAS Users' Guide. SAS Institute Inc., Cary, NC.

Simitzis, P. E., J. A. Bizelis, S. G. Deligeorgis, and K. Feggeros. 2008. Short communication: Effect of early dietary experiences on the development of feeding preferences in semi-intensive sheep farming systems - A brief note. Appl. Anim. Behav. 111:391-395.

Squibb, R. C., F. D. Provenza, and D. F. Balph. 1990. Effect of age of exposure on consumption of a shrub by sheep. J. Anim. Sci. 68:987-997.
Stobo, I. J. F., J. H. B. Roy, and H. J. Gaston. 1966a. Rumen development in the calf. 1 . The effect of diets containing different proportions of concentrates to hay on rumen development. Br. J. Nutr. 20:171-188.

Stobo, I. J. F., J. H. B. Roy, and H. J. Gaston. 1966b. Rumen development in the calf. 2. The effects of diets containing different proportions of concentrates to hay on digestive efficiency. Br. J. Nutr. 20:189-215.

Stone, W. C. 2004. Nutritional approaches to minimize subacute ruminal acidosis and laminitis in dairy cattle. J. Dairy Sci. 87:E13E26.

Tamate, H., A. D. McGilliard, N. L. Jacobson, and R. Getty. 1962. Effect of various dietaries on the anatomical development of the stomach in the calf. J. Dairy Sci. 45:408-420.

Van Soest, P. J., J. B. Robertson, and B. A. Lewis. 1991. Methods for dietary fiber, neutral detergent fiber and non-starch polysaccharide in relation to animal nutrition. J. Dairy Sci. 74:3583-3597.

Vazquez-Anon, M., A. J. Heinrichs, J. M. Aldrich, and G. A. Varga. 1993. Postweaning age effects on rumen fermentation end-products and digesta kinetics in calves weaned at 5 wk of age. J. Dairy Sci. $76: 2742-2748$.

Villalba, J. J., and F. D. Provenza. 1999. Effects of food structure and nutritional quality and animal nutritional state on intake behavior and food preferences of sheep. Appl. Anim. Behav. Sci. 63:145-163.

Warner, R. G., W. P. Flatt, and J. K. Loosli. 1956. Dietary factors influencing the development of the ruminant stomach. J. Agric. Food Chem. 4:788-792. 